\title{
Quality of Life in Patients with Type 2 Diabetes Mellitus in Bulgaria: A Cross - Sectional Study
}

\author{
Boryana Levterova $^{1,}$, , Georgy Levterov², Elena Dragova ${ }^{3}$ \\ ${ }^{1}$ Department of Health Management, Health Economic and General Practice, Medical University of Plovdiv, Plovdiv, Bulgaria \\ ${ }^{2}$ Clinic of Endocrinology and Metabolic Diseases, UMHAT "Kaspela” Ltd, Plovdiv, Bulgaria \\ ${ }^{3}$ Faculty of Public Health, Medical University - Plovdiv, Plovdiv, Bulgaria \\ Email address: \\ boriana_levterova@abv.bg (B. Levterova),glevterov@yahoo.com (G. Levterov), dragovaea@mail.bg (E. Dragova)

\section{To cite this article:} \\ Boryana Levterova, Georgy Levterov, Elena Dragova. Quality of Life in Patients with Type 2 Diabetes Mellitus in Bulgaria: A Cross - \\ Sectional Study. European Journal of Preventive Medicine. Vol. 4, No. 1, 2016, pp. 7-12. doi: 10.11648/j.ejpm.20160401.12
}

\begin{abstract}
Diabetes Mellitus is a disease that affects almost every aspect of patients' life. Socio-medical importance and continuously increasing financial costs of diabetes require a thorough research on the quality of life in these patients to optimize clinical management and increase the effectiveness of health interventions. The aim of the study is to assess the quality of life in patients with type 2 diabetes mellitus. Materials and A cross-sectional study was conducted in 90 patients with type 2 diabetes mellitus (T2DM) in Bulgaria. Health-related quality of life was measured using the 36-item Short-Form Health Survey (SF-36). The study result showed that the participants' age ranged from 32 to 88 years old, with mean of 63.0 years (standard deviation (SD) 0.96). Less than half were females (52.9\%), married (74.3\%) and living in urban areas (61.4\%). Diabetes negative impact is observed on all life aspects. The duration of disease (diabetes duration) and diabetes complication seem to be the most influential factors which negatively and statistically significant affect all the SF-36 subscales. It concluded that better quality of life of patients with diabetes mellitus type 2 is achieved by preventing complications and effective management of chronic underlying diseases.
\end{abstract}

Keywords: Quality of Life, Type 2 Diabetes Mellitus, Bulgaria

\section{Introduction}

Diabetes mellitus (DM) has become a major public health problem. The prevalence and incidence of DM have increased considerably over the past years - 382 million people have diabetes and the disease is set to rise beyond 592 million in fewer than 25 years [1]. The International Diabetes Federation (IDF) recently reported that the number of people with diabetes in the European Region is estimated to be $8.5 \%$ of the adult population and this is expected to increase to over $44 \%$ by 2035 [2].

Diabetes mellitus is associated with metabolic and vascular complications. These complications are responsible for most of the excess morbidity and mortality associated with the disease, and there are an estimated 51 million excess deaths per year attributable to the disease [2].

Diabetes and its complications represent a significant medical, social and economic problem. The disease requires high costs for its systematic control, for its contemporary treatment and late complications [3]. Increased morbidity from heart disease, renal failure and blindness vastly increase the direct and indirect medical costs associated with the disease. In Bulgaria it is estimated that the healthcare care expenditure for diabetes complications exceeds 2500 BGN per hospitalized person [4].

The prevalence of diagnosed diabetes among Bulgarians of all ages increased from $0.19 \%$ [5] to $9.55 \%$ in 2012 [6, 7]. About a quarter of person with diabetes are unaware that they have the disease. Nearly $85-95 \%$ of all diabetics in Bulgaria have type 2 diabetes mellitus (T2DM). The prevalence of undiagnosed diabetes in Bulgarian adults rises with age as diagnosed diabetes [8].

Patients with diabetes need special care and their absence can lead to physical and psychological disabilities, socioeconomic issues (including their families), change in quality of life and even to social exclusion [9].

The World Health Organization defines Quality of Life (QoL) as an individual's perception of their position in life in the context of the culture and value systems in which they live and in relation to their goals, expectations, standards and 
concerns [10]. QoL is a concept that includes subjective assessments of positive and negative aspects of life [11]. Health-related d Quality of life (HRQoL) includes perceptions of physical and mental health and their correlates, including health risks and conditions, functional status, social support and socio-economic status [12].

Diabetes can affect an individual's HRQoL from pathways involving impairment and disease progression, having a lifelong illness that requires lifestyle restrictions, and from being on medical therapies that impose side effects and possible treatment burdens. Diabetes is one of the leading causes of foot amputation, blindness, renal failure, and cardiovascular disease in Bulgaria [8].

Measuring the quality of life of patients with chronic conditions is important for assessing the effectiveness of clinical activity and management of these conditions. Clinical examination and diagnostics provide information about the patient's health and the progression or regression of disease. But each person perceives her/his quality of life differently and it is influenced not only by physical health, but also mental state, level of dependence on others through service, social relationships, personal beliefs and the relationship with the environment. DM can have a profound impact on the health status and QoL of patients in terms of physical, social, and psychological well-being and their measurement is an important part of the care provided and disease management $[13,14]$.

The aim of this study was to evaluate the quality of life and the factors affecting it in diabetic patients with type 2 diabetic mellitus.

\section{Material and Methods}

The cross - sectional study was conducted at outpatient practices from June to September 2012 from T2DM patients. The survey was conducted within a 4-month period in the territory of the Plovdiv (the second largest region in Bulgaria). The subjects were invited to participate after their usual doctor's visit in practices specializing in endocrinology and metabolic diseases and collected information via selfcompleted questionnaire, clinical observation and by reviewing the patient's' medical records, as it has been suggested that these data sources supplement each other in providing reliable clinical data Health-related QOL of patients was measured using the 36-item Short-Form Health Survey (SF-36), (License Agreement: QM013448/2012). All procedures performed in studies involving human participants were in accordance with the ethical standards of the Research and Ethics Committee of the Medical University - Plovdiv and with the Helsinki declaration.

Random samples of 90 registrants of this practice are invited to participate in the study. 70 of them completed the questionnaire (response rate $78 \%$ ). Inclusion criteria were as follows: age over 18 years of age, diagnosed with diabetes mellitus type 2, able to self-complete the questionnaire in Bulgarian. Respondents with type 1 diabetes, patients with impaired cognitive abilities and gestational diabetes were excluded.

The respondents were asked to complete the Bulgarian version of the SF-36v2 and questions on socio-demographic information (age, sex, ethnicity, and level of education, employment status, smoking status, and marital status), any diabetes complications, other chronic conditions, diabetes therapy and duration of diabetes. Clinical data were collected by subject's medical records (body weight, height).

Health-related quality of life was measured using the 36item Short-Form Health Survey from the Medical Outcomes Study 36-item Short-Form Health Survey (SF-36) [15-17]. The SF-36 is one of the most widely used tools for assessing health-related quality of life. It is sometimes referred to as the "gold standard" for health status measurement. The SF36 scale works best as a health profile measure with eight dimensions, rather than a single summative measure. Questions in the eight health dimensions evaluate the degree to which an individual's health effects:

1. Physical functioning (PF);

2. Social functioning $(\mathrm{SF})$;

3. Bodily pain (BP);

4. Role limitations caused by physical health problems (Role/physical) (RF);

5. Role limitations caused by emotional problems (Role/emotional) (RE);

6. Emotional well-being (Mental health) $(\mathrm{MH})$;

7. Energy/fatigue (Vitality) (VT);

8. General health perceptions $(\mathrm{GH})$.

Each domain provides a score from 0 to 100 with zero indicating the worst health status and 100 the best. The questionnaire is based on a WHO definition of health, which states that health is not only defined by the absence of disease and infirmity, but also by the presence of physical, mental, and social well-being [18]. The scales were scored using a Likert's method of summated ratings. Each item was assumed to have a linear relationship with the score for its domain. The eight scales of the SF-36vbul questionnaire have been shown to have high internal consistency (Cronbach Alpha 0.76-0.96). All items were used to calculate the physical and mental component summary scores, by applying a scoring algorithm empirically derived from the data of a US general population survey The SF-36 health assessment questionnaire has been reported as valid and reliable in normal populations as well as diabetes patient groups [19-21]. The categorical data such as gender, comorbidities, and level of education are presented in frequency and percentage. Internal consistency reliability of each scale was calculated using Cronbach's alpha. Normality was tested with the Kolmogorov-Smirnov test. Subscale scores were compared within groups, using Mann-Whitney and Kruskal-Wallis nonparametric tests, for each sociodemographic and diabetes-related independent variable. Significance was defined as $\mathrm{P}$ value $\leq 0.05$ for each outcome measure. Data collected from the second part of the study were entered into an Excel spread sheet (Microsoft Corporation, Redmond, WA). Descriptive and inferential statistics were conducted by using SPSS version 17.0. Data 
analyses involved descriptive statistics in order to calculate frequencies, means and standard deviations for each variable. Analyses of the relationship between independent variables and HRQoL were performed to establish those variables associated with HRQoL.

\section{Results}

The participant's age ranged from 32 to 88 year old, with mean of 63 years old (Standard deviation (SD) 0.96). Among the 70 respondents, less than half were female $(53 \%)$, married (74\%) and living in urban areas (61\%). Fifty percent of the respondents were in the age-group of 50-59 years. The majority $(60 \%)$ were from the low socioeconomic status. More details about the respondents' characteristics are shown in Table 1.

Table 1. Characteristics of respondents $(n=70)$.

\begin{tabular}{|c|c|c|}
\hline Characteristics & $\mathbf{n}$ & $\%$ \\
\hline \multicolumn{3}{|l|}{ Sex } \\
\hline Female & 37 & 52.9 \\
\hline Male & 33 & 47.1 \\
\hline \multicolumn{3}{|l|}{ Education } \\
\hline Primary education & 17 & 24.3 \\
\hline Secondary education & 32 & 45.7 \\
\hline College and High & 8 & 11.5 \\
\hline Non response & 13 & 18.5 \\
\hline \multicolumn{3}{|l|}{ Ethnicity } \\
\hline Bulgarian & 58 & 82.9 \\
\hline Turkish & 7 & 10.0 \\
\hline Roma & 5 & 7.1 \\
\hline \multicolumn{3}{|l|}{ Marital status } \\
\hline Married & 52 & 74.3 \\
\hline Single /Widowed/ Divorced & 18 & 25.8 \\
\hline \multicolumn{3}{|l|}{ Employment status } \\
\hline Employed & 23 & 32.9 \\
\hline Retired & 39 & 55.7 \\
\hline Unemployed & 8 & 11.4 \\
\hline Duration of $\mathrm{T} 2 \mathrm{DM}>5$ years & 43 & 61.4 \\
\hline \multicolumn{3}{|l|}{ Complication } \\
\hline Neuropathy & 12 & 17.1 \\
\hline Retinopathy & 9 & 12.9 \\
\hline Nephropathy & 3 & 4.3 \\
\hline Ischemic Heart disease & 31 & 44.3 \\
\hline Chronic conditions & 68 & 97.1 \\
\hline Hypertension & 53 & 75.7 \\
\hline Dyslipidemia & 28 & 41.0 \\
\hline Smoking & 6 & 8.6 \\
\hline \multicolumn{3}{|l|}{ DM treatment } \\
\hline Diet & - & - \\
\hline Oral only & 56 & 80.0 \\
\hline Oral + insulin injections & 8 & 11.4 \\
\hline \multirow[t]{2}{*}{ Insulin only } & 6 & 8.6 \\
\hline & Mean (SD) & Range \\
\hline Age & $63.0(0.9)$ & $32-88$ \\
\hline $\mathrm{BMI} *(\mathrm{~kg} / \mathrm{m} 2)$ & $30.6(5.1)$ & $21.2-43.6$ \\
\hline $\mathrm{HbA} 1 \mathrm{c} * *$ & $8.08(0.8)$ & $6.1-13.8$ \\
\hline
\end{tabular}

*BMI= Body Mass Index; **HbA1c= Hemoglobin $\mathrm{A}_{1} \mathrm{c}$
Comorbidities were reported by $97 \%$ of the participants and the most commonly reported medical conditions were hypertension (76\%) followed by Ischemic heart disease (44\%). They had chronic complications such as diabetic neuropathy (17\%) followed by diabetic retinopathy (13\%). Eighty percent of the patients control their disease by oral therapy.

Regarding age, only PF scores deteriorate significantly in the older age-groups $(\mathrm{P}<0.001)$. Fig. 1 explains the gender quality of life. Male respondents perceived a better quality of life compared to women, especially in SF, RE and $\mathrm{MH}$. Analysis showed statistically significant gender-related differences in all areas. Overall, the SF-36 score was lower (51.5) in females than in males (62.1) and this difference was statistically significant $(\mathrm{P}<0.05)$.

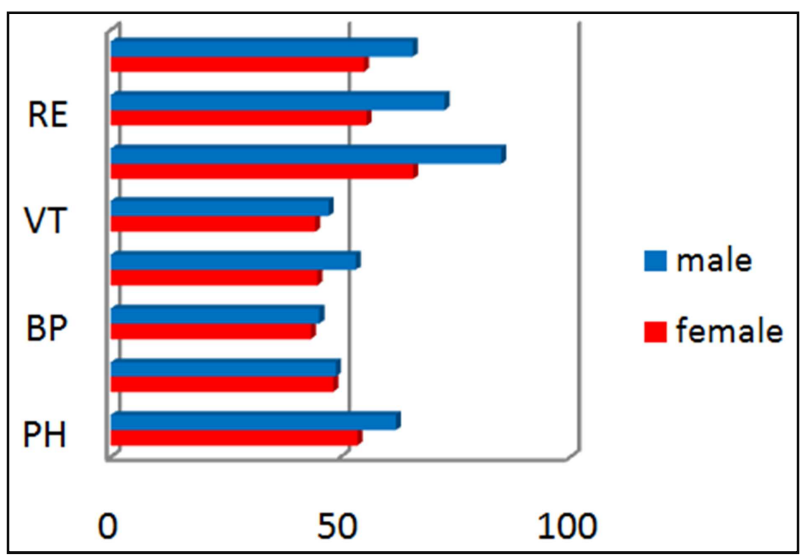

Figure 1. Gender-related $S F-36$ score in type 2 diabetic patients $(n=70)$.

Married patients reported better health in all areas and the differences are substantial BP, VT and MH $(\mathrm{P}<0.05)$. Single (Widowed/Divorced) reported poor mental health that may be associated with a lack of emotional support from a partner and loneliness.

Correlation between the level of education and quality of life in type 2 diabetic patients is given in Fig 2. There was no statistically significant difference in the quality of life of patients with diabetes compared to the level of education in $\mathrm{GH}$ and RE.

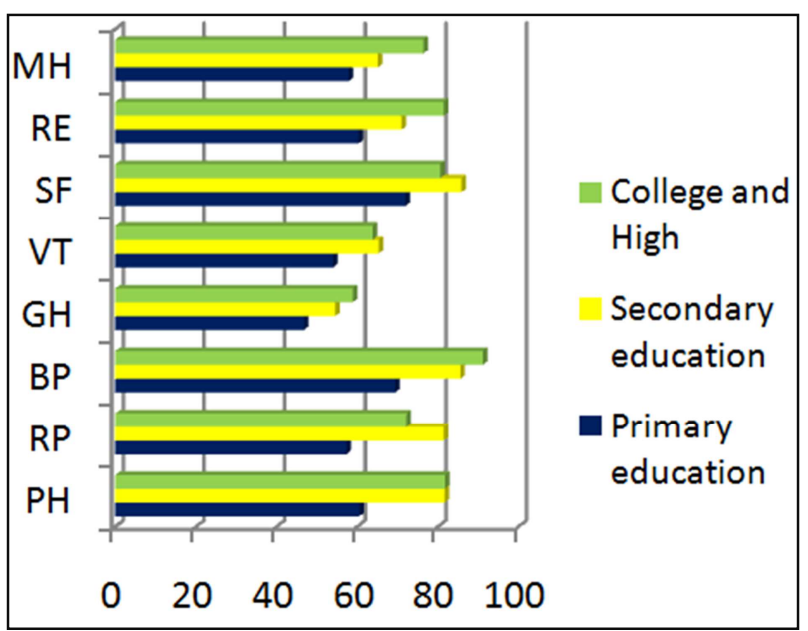

Figure 2. QoL in T2DM patients and their level of education $(n=70)$. 
The resulting profile in terms of "employment status" shows statistically significant differences in the three subscales - PF, $\mathrm{BP}$ and SF. People who are employed have the highest score for GH. Retired show the lowest value in the RE.

Duration of disease (diabetes duration) seems to be the most influential factor which negatively and statistically significant affects all the SF-36 subscales, particularly in the case of the group of prescription "5 and more years". Fig. 3 explains the influence of disease duration on the parameters of quality of life. The best quality of life in all areas was observed with diabetes duration less than 3 years, but no statistically significant in RP, VT, SF, and MH ( $p>0.05)$.

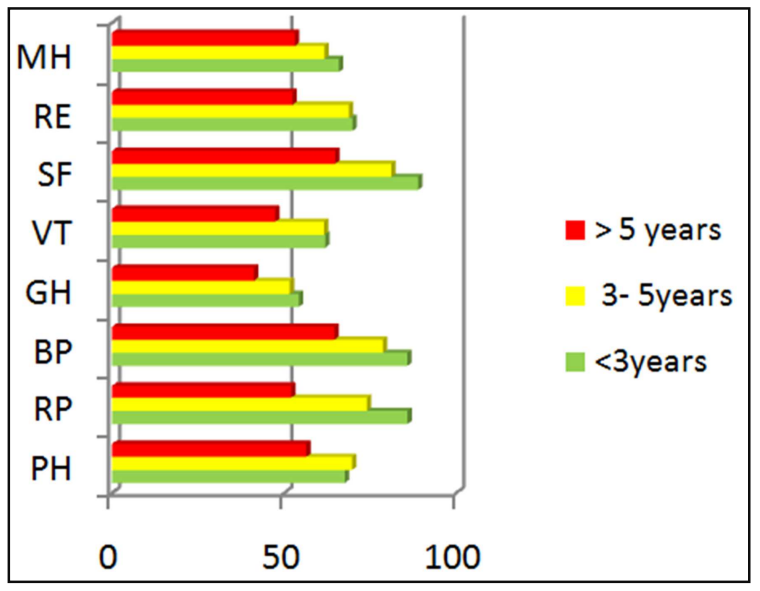

Figure 3. QoL in T2DM patients and diabetes duration

Patients reported higher results for QoL with BMI in the "normal" range (18.5 to $24.9 \mathrm{~kg} / \mathrm{m}^{2}$ ) than those with "overweight" and "obese" range, but the differences are statistically significant only for the PF scale. The patients with comorbidity have lower quality of life score in all domains compared to the group without comorbidity. The most prevalent comorbidities are shown in Table1. Micro and macro vascular complications also show a negative impact on all the domains. Out of eight domains in the SF-36 questionnaire, the two most affected domains are SF and PF. The two domains that are least affected were VT and GH. This difference is found to be statistically significant $(\mathrm{P}<0.01)$.

\section{Discussion}

Although diabetes is known to be a serious burden for the Bulgarian system of public health, there are still quite scarce studies that assess the impact of diabetes on the patients' quality of life of patients. It is very important for medical and clinical disciplines to examine the quality of life and find opportunities to improve it.

The study examined the relationship of demographic, social factors and health indicators in adult patients with diabetes mellitus type II, living in the Plovdiv region.

This research has shown that the most frequent comorbidities in T2DM are hypertension (76\%), dyslipidemia (41\%), ophthalmological complications (13\%), and diabetic polyneuropathy in $17.1 \%$ of patients. The results of this study are in corresponding with previous studies [22-27].

We investigated the association of demographic, social and diabetes-specific variables on the QOL of T2DM patients in Bulgaria. The SF-36 and its eight domains scores were found to have statistically significant association with gender, marital status and education. Males have higher SF-36 scores than females in all eight domains corresponding with previous results [28, 29]. Chittleborough et al. reported similar findings in an Australian population, where the QoL scores among males were higher in all domains, except in $\mathrm{GH}$ and VT [29]. Woodcock et al. in the UK too, except in BP [30]. Our study shows that men have a better quality of life compared to women, with statistically important difference in the domain of vitality and pain. Better social life and physical activity might contribute to higher satisfaction levels in men. Studies have shown that men were more confident of their ability to control diabetes and reported a higher quality of life and were less likely to get depression or anxiety compared to women [31, 32]. Females' mental and physical structure, in addition to subjectivity of the self-administered quality of life score, may justify this finding. Also, women tend to be more expressive and thus they are more likely to complain about a poor quality of life. Significant effect of gender on the QoL in diabetic patients has been demonstrated in other studies [33]. We investigated this association only in PF domain. Rubin et al. reported that a number of socio-demographic variables affect the selfassessment of quality of life: men generally reported better quality of life than women; young people generally reported better quality of life than adults; those with higher education and higher income generally report better quality of life [9].

The results of our study show statistically important impact of the level of education on the life quality of patients with diabetes. Studies have confirmed the linear correlation between the level of education and quality of life [34, 35]. Data analysis showed that age, gender, marital status and education are important factors influencing the selfassessment of quality of life, allowing to be made a specific profile of patients and their needs for the development of adequate approaches to health education.

We found that the effect of diabetes on HRQoL was generally mild, with greater impact on the SF-36 scales measuring physical (PF, RF, BP, GH, RE) relative to mental health components (VT, SF and $\mathrm{MH}$ ). This was not surprising, given that our subjects were recruited from the outpatients practice.

Statistically significant lower quality of life was verified in elderly patients (over 65 years of age) and longer treatment duration. The reason for low quality of life in diabetic patients lies in the fact that the elderly people usually have more than one chronic disease, which means that they are taking several medications at the same time, and have cognitive complications, as well [9, 34-36].

As regards to QoL in those with duration of diabetes of more than 5 years, we found that these subjects had lower scores in all domains. Overall, the SF-36 score was significantly lower among respondents with complications as 
compared to respondents with no complication; PF, GH, VT and SF were affected more and the differences were statistically significant. Woodcock et al. [30] also observed better scores in all domains (except RP and BP) in those without complications.

Poor quality of life reported patients with micro vascular complications (such as polyneuropathy), those with a longer duration of the disease and comorbidities. Many researchers identify factors associated with the disease as the strongest predictors of adverse QoL [9, 25-27, 35-36].

We also found that with the exception of subjects with diabetes and heart disease, the presence of co-existing chronic medical conditions in subjects with diabetes generally resulted in further significant lowering of HRQoL. Our results are important because they demonstrate that the impact of these co-existing chronic medical conditions in diabetes is not only in increasing healthcare costs [37] and mortality [38] but also in increasing the physical and psychosocial burden of diabetes. Given that complications of diabetes constitute the majority of chronic medical conditions commonly present in subjects with diabetes, our findings further underscore the importance of preventing and treating complications of diabetes, and also highlight the need to identify factors that may be modulated to improve HRQoL in these subjects.

The major limitation of this study is the cross-sectional design which only provided information about associations but did not present causality between some of the variables. Furthermore, the small sample size may limit the power for some of the comparisons concerning the presence or absence of complications.

\section{Conclusion}

High quality of life represents the ultimate goal and is important outcome of all medical interventions in diabetic patients. Age, gender, marital status and education are important factors influencing the self-assessment of quality of life, allowing to be made a specific profile of patients and their needs to develop adequate approaches to health education. But socio-demographic characteristics of the participants have lower influence on QoL, compared to disease specific indicators in Bulgaria.

\section{Acknowledgments}

We gratefully acknowledge the patients for their kind participation in the study and the endocrinologists for their dedicated participation in data collection. We would like to thank D. Dimitrova, MSc, MSSc, $\mathrm{PhD}$, for her suggestion and advice in the study.

\section{References}

[1] Guariguata L, Whiting DR, Hambleton I, Beagley J, Linnenkamp U, Shaw JE. Global estimates of diabetes prevalence for 2013 and projections for 2035. Diabetes Res Clin Pract. 2014; 103(2): 137-49.
[2] IDF. Diabetes Atlas. 6th ed. 2013. Available: https://www.idf.org/sites/default/files/EN_6E_Atlas_Full_0.pdf.

[3] American Diabetes Association. (2013). Economic costs of diabetes in the US in 2012. Diabetes Care. 2013; 36(4): 1033-46.

[4] Valov V, Doneva M, Borisova AM, Tankova T, Czech M, Manova M, Savova A, Peikova L, Petrova G. Regional differences in diabetic patients' pharmacotherapy in Bulgaria. Eur Rev Med Pharmacol Sci. 2014; 18(10): 1499-506.

[5] Koeva L, Koev D. Epidemiology of diabetes mellitus in Bulgaria. Biomed Rev J. 1996; 5: 57-63.

[6] Borissova, A-M, Shinkov A, Kovatcheva R, Vlahov J, Dakovska L, Todorov T. Changes in the Prevalence of Diabetes Mellitus in Bulgaria (2006-2012). Clin Med Insights Endocrinol Diabetes. 2015; 8: 41-5.

[7] Borissova A-M, Shinkov A, Vlahov J, Dakovska L, Blajeva E, Todorov T. Prevalence of Diabetes Mellitus and Prediabetes in Bulgaria Today. Endorcinologia. 2012; 12 (4): 182-92. (In Bulgarian).

[8] Borisova A-M, Zaharieva S, Tankova T. Recommendations for good clinical practice in diabetes. Bulgarian Society of endocrinology; 2013. (In Bulgarian).

[9] Rubin RR, Peyrot M. Quality of life and diabetes. Diabetes Metab Res Rev 1999; 15: 205-18.

[10] The World Health Organization Quality of Life Assessment (WHOQOL): development and general psychometric properties. Soc Sci Med. 1998; 46 (12): 1569-85.

[11] Bradley C. Importance of differentiating health status from quality of life. Lancet. 2001; 357 (9249): 7-8.

[12] Moriarty DG1, Zack MM, Kobau R. The Centers for Disease Control and Prevention's Healthy Days Measures - population tracking of perceived physical and mental health over time. Health Qual Life Outcomes. 2003; 1: 37.

[13] Testa MA, Simonson DC. Assessment of quality-of-life outcomes. N Engl J Med. 1996; 334 (13): 835-40.

[14] IDF. Global guideline for managing older people with type 2 Diabetes, 2013. Available: http://www.idf.org/sites/default/files/IDF-Guideline-for-olderpeople-T2D.pdf.

[15] Ware JE Jr, Sherbourne CD. The MOS 36-item short-form health survey (SF-36). I. Conceptual framework and item selection. Med Care. 1992; 30(6): 473-83.

[16] McHorney CA, Ware JE Jr, Raczek AE. The MOS 36-Item Short-Form Health Survey (SF-36): II. Psychometric and clinical tests of validity in measuring physical and mental health constructs. Med Care. 1993; 31(3): 247-63.

[17] McHorney CA, Ware JE Jr, Lu JF, Sherbourne CD. The MOS 36-item Short-Form Health Survey (SF-36): III. Tests of data quality, scaling assumptions, and reliability across diverse patient groups. Med Care. 1994; 32(1): 40-66.

[18] Preamble to the Constitution of the World Health Organization as adopted by the International Health Conference, New York; 1946; signed on 22 July 1946 by the representatives of 61 States (Official Records of the World Health Organization, no. 2, p. 100) and entered into force on 7 April 1948. The Definition has not been amended since 1948. 
[19] Ware JE, Kosinski M, Bayliss MS, McHorney CA, Rogers WH, Raczek A. Comparison of methods for the scoring and statistical analysis of SF-36 health profile and summary measures: summary of results from the Medical Outcomes Study. Medical care. 1995; 33(4 Suppl): AS264.

[20] Levterova B, Dimitrova D, Levterov G, Videnova E. Measuring the quality of life in patients with type 2 diabetes mellitus. Plovdiv: Science and youth; 2013. (In Bulgarian).

[21] Kazis LE, Miller DR, Clark JA, Skinner KM, Lee A, Ren XS, Spiro A 3rd, Rogers WH, Ware JE Jr. Improving the response choices on the veterans SF-36 health survey role functioning scales: results from the Veterans Health Study. J Ambul Care Manage. 2004; 27(3): 263-80.

[22] Holden L, Lee C, Hockey R, Ware RS, Dobson AJ. Longitudinal analysis of relationships between social support and general health in an Australian population cohort of young women. Qual Life Res. 2015; 24 (2): 485-92.

[23] Bardage C, Isacson DG.). Hypertension and health-related quality of life. an epidemiological study in Sweden. J Clin Epidemiol. 2001; 54 (2): 172-81.

[24] Orbetsova M, Stoilov P, Vassileva E, Gruev L, Raynov E et al. Atherogenic risk factors and socially significant disease. Sofia: Heart and Health; 2005.

[25] Maddigan SL, Feeny DH, Johnson JA. Health-related quality of life deficits associated with diabetes and comorbidities in a Canadian National Population Health Survey. Qual Life Res. 2005; 14 (5): 1311-20.

[26] Wexler DJ, Grant RW, Wittenberg E, Bosch JL, Cagliero E, Delahanty L, Blais MA, Meigs JB. Correlates of healthrelated quality of life in type 2 diabetes. Diabetologia. 2006; 49 (7): 1489-97.

[27] Papadopoulos AA, Kontodimopoulos N, Frydas A, Ikonomakis E, Niakas D. Predictors of health-related quality of life in type II diabetic patients in Greece. BMC Public Health. 2007; 7: 186.

[28] Spasić A, Radovanović RV, Đorđević AC, Stefanović N, Cvetković T. Quality of Life in Type 2 Diabetic Patients. Acta Facultatis Medicae Naissensis. 2014; 31(3): 193-200.
[29] Chittleborough CR, Baldock KL, Taylor AW, Phillips PJ; North West Adelaide Health Study Team. Health status assessed by the SF-36 along the diabetes continuum in an Australian population. Qual Life Res. 2006; 15(4): 687-94.

[30] Woodcock AJ, Julious SA, Kinmonth AL, Campbell MJ; Diabetes Care From Diagnosis Group. Problems with the performance of the SF-36 among people with type 2 diabetes in general practice. Qual Life Res. 2001; 10(8): 661-70.

[31] Ali S, Stone MA, Peters JL, Davies MJ, Khunti K. The prevalence of co-morbid depression in adults with Type 2 diabetes: a systematic review and meta-analysis. Diabet Med. 2006; 23 (11): 1165-73.

[32] Goldney RD, Phillips PJ, Fisher LJ, Wilson DH. Diabetes, depression, and quality of life: a population study. Diabetes Care. 2004; 27 (5): 1066-70.

[33] McCollum M, Hansen LS, Lu L, Sullivan PW. Gender differences in diabetes mellitus and effects on self-care activity. Gend Med. 2005; 2(4): 246-54.

[34] Al Hayek AA, Robert AA, Al Saeed A, Alzaid AA, Al Sabaan FS. Factors Associated with Health-Related Quality of Life among Saudi Patients with Type 2 Diabetes Mellitus: A CrossSectional Survey. Diabetes Metab J. 2014; 38 (3): 220-9.

[35] Glasgow RE, Ruggiero L, Eakin EG, Dryfoos J, Chobanian L. Quality of life and associated characteristics in a large national sample of adults with diabetes. Diabetes Care. 1997; 20(4): $562-7$.

[36] Thommasen HV, Berkowitz J, Thommasen AT, Michalos AC. Understanding relationships between diabetes mellitus and health-related quality of life in a rural community. Rural Remote Health. 2005; 5 (3): 441.

[37] Williams R, Van Gaal L, Lucioni C. Assessing the impact of complications on the costs of Type II diabetes. Diabetologia. 2002; 45 (7): S13-S17.

[38] Haffner SM, Lehto S, Rönnemaa T, Pyörälä K, Laakso M. (1998). Mortality from coronary heart disease in subjects with type 2 diabetes and in nondiabetic subjects with and without prior myocardial infarction. New England journal of medicine. 1998; 339 (4): 229-34. 